\title{
The Effects of Self-Esteem and Influence of Friends via Social Media on Body Image Amongst Children
}

\author{
Arman $\mathrm{Hj} \mathrm{Ahmad}^{1}$, Izian Idris ${ }^{2}$ \& Regina Moy Li Jing ${ }^{2}$ \\ ${ }^{1}$ Department of Marketing, Universiti Kuala Lumpur Business School, Malaysia \\ ${ }^{2}$ Department of Marketing, Sunway University Business School, Malaysia \\ Correspondence: Arman Hj Ahmad, Department of Marketing, Universiti Kuala Lumpur Business School, \\ Malaysia.
}

Received: April 30, 2019

Accepted: May 30, 2019

Online Published: June 10, 2019

doi:10.5430/ijfr.v10n5p40

URL: https://doi.org/10.5430/ijfr.v10n5p40

\begin{abstract}
Introduction: With the rise and fall of many communication platforms embedded into our everyday lives and the on-going maturity of the digitalization era, social media usage has tremendously increased over the past decade. The purpose of this research is to identify to what extent self-esteem and the influence of friends' impact children's perception of their body image through social media and how powerful social media in influencing the body image of children.

Methodology: The theoretical implication of this study is to expand the usage of Signalling theory, Sociocultural theory and Social Comparison theory towards better explaining children's behaviours and the factors that impact children view of their body image. 282 children were recruited using the snowball sampling technique and data collected were analysed using Smart-PLS to see the impacts and relationship between all variables.

Results: This study found that the self-esteem and friends do impacts body comparison on social media. However, the self-esteem is negatively correlated. The study also identified that there is a significance direct relationship between the direct impacts of self-esteem and friends towards the body image. On the other hand, the social media is found to have no direct impact on body image.

Conclusion/- and Recommendations: This study provides a better insight for the government on the importance of regulation of advertisements particularly via social media and for the society at large to create a more socially supportive environment for adolescents to communicate and help them grow their mind-set on the acceptable and realistic standards of beauty as well as contributes to the existing knowledge on the role of social media and adds knowledge to how powerful social media in giving impacts to body image among adolescences.
\end{abstract}

Keywords: body image, self-esteem, friend influence, social media, sociocultural theory, social comparison theory, signalling theory, Malaysia

JEL Classification: M31

\section{Introduction}

Social media has been studied and found to be a double-edged sword, affecting children both positively and negatively. It is depending on the type of exposure at a far greater magnitude of impact during childhood than at any other stage of human life cycle, regardless of their gender through, friend influence and an individual's self-esteem. Most studies have been conducted in the Western context and the majority of the research focuses on women. This study fills the gap of researching on the impact of friend influence and media portrayal on social media amongst children or Generation $\mathrm{Z}$ who are rising to become the largest generation with the next biggest spending power. The purpose of this research is to identify to what extent self-esteem and the influence of friends' impact children's perception of their body image through social media and how powerful social media in influencing the body image of children.

\section{Literature Review}

\subsection{Body Image (Body Satisfaction-Dissatisfaction)}

Grammas and Schwartz (2009); Cash and Pruzinsky, (2004) stated that body image is the internal, subjective 
representation of physical appearance and body experience dramatically influences quality of life. Body image is shaped by the cognitive, emotional, perceptual and behavioural domains which affect a person's mood, physical experience and environment (Croll, 2005, Phillips, 2005). Tiggemann and Slater (2013) concluded that having a negative perception of one's body image is shaped by an increase in media exposure, but not as impactful as the degree of exposure to appearance-specific media i.e. that a higher degree of exposure to appearance-specific media, correlates to a high impact on the way a person perceives their body image, and that this is often conveyed in a negative light (Meier and Gray, 2014). People develop physiologically in areas, including self-perception - this is happening during a person's adolescence phase (Croll, 2005). Concurrently, adolescents will experience puberty which has a tendency to adversely affect a healthy body image (Mulgrew et al., 2014; Kantanista et al.,2015). In a psychological context, the adolescence period of a person's lifecycle is when one forms ideological (i.e. values) and interpersonal processes i.e. relationships (Balistreri et al., 1995); where a stronger interpersonal identity commitment would result in a positive body image (Jermsittiparsert, Sriyakul \& Pamornmast 2012; Wängqvist and Frisén, 2013). Petrie et al. (2010) noted that various biological, psychological and social variables (e.g. BMI, self-esteem, pubertal development, internalisation, social comparison, and physical-self-concept) have impacts body image among children on the spectrum of body satisfaction-dissatisfaction.

Based on past research, cultural messages (Voelker et al., 2015; Ismail, Sabran \& Ariffin 2018) and societal standards (Benton and Karazsia, 2015; Rafindadi \& Kondo 2018) of appearance and attractiveness are equally as influential. Those present in an adolescent's immediate environment (i.e. family, peers and romantic partners) can reinforce such factors- cultural messages and societal standards (Voelker et al., 2015). Peer influence is identified to be a prominent source of imparting negative body image (i.e. body dissatisfaction) via appearance based teasing and criticism, modelling and discussing appearance concerns, making appearance comparisons, judging the appearance of friends, and social conflict or exclusion (Webb and Zimmer-Gembeck, 2014). Other factors affecting body image amongst adolescents such as 'thin and lean female images' and 'strong and lean male images' are the norm for westernised societies (Croll, 2005, Benton and Karazsia, 2015; Rauf, 2016). This factor is heavily influenced by media's portrayal of unrealistic standards affirmed by role models such as influencers, movie and television stars, athletes and models (Koyuncu et al., 2010). Adolescents exposed to thin-ideal (females) and muscularity-ideal (males), through sources such as movies and music videos, were reported to have the highest body dissatisfaction (Croll, 2005, Ferguson et al., 2014).

\subsection{Signalling Theory}

Signalling theory is a framework to better understand how information is disclosed on user social media profiles and what is not directly observable (Ahn, 2011, Donath, 2007). The signalling model includes three primary actors: (1) the high-quality signaller who decides whether and how to signal the information, (2) the low-quality signaller- the receiver who observes and interprets the signal (Pyrooz and Densley, 2016; Rosli \& Siong 2018). According to Bacharach and Gambetta (2001), signals are intentional features of agents that provide information to observers such as education level, number of friends, and frequency of engagement are all signals and they are "hard-to-fake". Signalling is the act of communicating to others one's identity, social status and social ties (Leeson, 2009, Kaminski, 2010; Islam, et. al., 2018). Interpersonal influence has an impact on regular consumption. Two dimensions of susceptibility to interpersonal influence have been theorised namely, normative interpersonal influences and informational interpersonal influences. Even in the absence of direct visibility of one's self from the public eye, consumers will still have the tendency to attempt to promote themselves in a positive light (Han et al., 2010). Normative interpersonal influences are the tendency of an individual to comply with the positive expectations of others by enhancement of self-image to associate with a reference group, achieve rewards or avoid punishment. While informational influence refers to a person's tendency to accept information from others as credible evidence through knowledge request or observation (Hoffmann and Broekhuizen, 2009, Chang et al., 2015, Shukla and Banerjee, 2014, Kastanakis and Balabanis, 2014).

\subsection{Impact of Self-Esteem on Social Media}

Robinson et al. (2013) defines self-esteem as the magnitude of which a person values, approves and likes oneself; which has also been coined as self-acceptance, self-worth, self-love, self-respect, self-efficacy, and life satisfaction (Best et al., 2014; Hye \& Lau 2018). Self-esteem is has been noted to be a fairly stable trait that develops over time and fluctuates in response to daily events and context (Heatherton and Polivy, 1991). Young people's self-esteem is greatly affected by their peer, especially those who link their self-worth to approval from others (Rosenberg, 1965). Although many studies have been conducted in the past, there has been different outcome on the relationship of self-esteem and social media use among adolescents, either positive, negative and no significant relationship 
(Apaolaza et al., 2013, Neira et al., 2014, Davenport et al., 2014). Given that a significant part of adolescents' interactions with their peers occur via social media, i.e. Facebook, Snapchat and Instagram (Valkenburg and Piotrowski, 2017), they are susceptible to receiving positive and negative feedback. This has a direct correlation to self-esteem, in a more public setting (Woods and Scott, 2016, Vogel et al., 2014, Sampasa-Kanyinga and Lewis, 2015). The portrayal of celebrities on social media has also brought about a "modern epidemic" such as narcissism as teenagers perceive fame and richness to be the highest achievement in life (Germain, 2017, Burgo, 2016; Inusah, 2018). An adolescent's exposure towards advertising efforts that celebrate ultra-thin (female)/muscular (male) models, appearance-focused conversations, picture sharing and fashion-focused postings on social media platforms exerts a significant impact on the development of the thin-ideal for the females, and muscular and athletic for the males (Perloff, 2014). Consumers consciously change their value and lifestyle to emulate the celebrity who is a target of upward comparison (Jermsittiparsert, Sriyakul\& Pamornmast2012; Fraser and Brown, 2002, Jin and Phua, 2014).

$\mathrm{H}_{1}$ : Self-esteem has a significant impact towards body comparison on social media.

$\mathrm{H}_{2}$ : Self-esteem has a significant impact towards body image.

\subsection{Social Comparison Theory}

Naturally, humans judge their personal abilities based on a comparison made against others because of the subjectivity of information (Hoorens and Damme, 2012, Dijkstra et al., 2008). Social comparison theory states that comparisons are made by individuals to validate judgements and reduce uncertainty (Festinger, 1954, Van Rooy et al., 2016). Past research has concluded that comparisons often occur with others who are worse (downward comparison) or better (upward comparison) instead of those equal on a desired trait (lateral comparison) (Hanus and Fox, 2015; Idrees, et. al., 2018). Upward comparisons more commonly cause an individual to feel inadequate, have poorer self-evaluation and experience negative effects. On the contrary, downward comparisons more commonly brings rise to feelings of superiority and positive self-evaluation (Vogel et al., 2014, Hanus and Fox, 2015).

Apart from reasons of self-evaluation, it is also predicted that social comparison may be motivated by self-enhancement or self-improvement.(Dijkstra et al., 2008; Inchamnan,2018). Self-enhancement influences social comparison when there is high cognitive demand (making connections, analysing information, and drawing conclusions). There is a tendency for people to assimilate where people want a sense of belonging and association to a group to create a social norm within that social structure in reducing discrepancies (Festinger, 1954, Magee and Smith, 2013).

\subsection{Vygotsky's Sociocultural Theory}

Sociocultural theory contends that dissatisfaction with physical appearance stems from the following conditions (Morrison et al., 2004): (1) The thin body ideal is promulgated in Western societies (Swami et al., 2010); (2) The tendency for women to adopt the ideology of "body as object" rather than "body as process"; and (3) The assumption that being thin equates to being attractive while being fat equate to being unattractive. The theory Morrison et al. (2004) supports the aforementioned theory by stating that sociocultural influences such as media images in particular have an impact on body image and eating disorders in women, and increasingly in men. Sociocultural influences derive of sexual objectification via media and interpersonal pressures (i.e. peers, parents and media) towards body evaluation (Tylka and Sabik, 2010, Ingolfsdottir et al., 2014). However, Yang (2013) exclaimed that ethnicity representation within the media would exude more positive self-evaluation because in the Asian context, adopting Westernised standards of physical beauty may be considered difficult to attain for Asians and vice versa. Asians are more susceptible towards thin-ideal as the cultural beauty norm which has been supported in many previous studies (Yang, 2013, Haboush et al., 2012, Swami et al., 2010). Women are subjected to the thin-ideal, which involves women possessing a thin hourglass shape while men's standard of attractiveness would indicate a muscular build characterised by a V-shape (well-developed upper body and a slender lower body) (Boisvert and Harrell, 2010, Vilhjalmsson et al., 2012, Singh et al., 2010). Non-weight-related appearance trends such as tanning have also been researched as one of the characteristics of being attractive for more positive impression (Yoo and Kim, 2012). On the other hand, factors such as aging and a wider waist-hip ratio are non-weight-related factors that are defined as unattractive (Haboush et al., 2012, Singh et al., 2010).

\subsection{Impact of Friend Influence on Social Media}

Friend influence is quite powerful and strong especially during one's adolescence. It is the time of new identities, friendship where peer group affiliations are solidified and parental influences gradually dilute (Simons-Morton and Farhat, 2010). Social media platforms offer an array of features that mediates users to build and maintain relationships with other users at their convenience (Ahn et al., 2007; Jermsittiparsert, Sriyakul \& Pamornmast 2012). 
The broader connectivity of social media platforms reinforces users to accumulate social capital. While the time-saving factor is what motivates users to disclose personal information in the online environment which aids in maintaining relationships (Ellison, 2007). Lampe et al. (2007) demonstrated that, an increase in self-disclosure sends desired signals to others and increases the impression of trustworthiness in accordance to interpersonal theories of building new relationships (Christofides et al., 2009). With increased accessibility of social media platforms through mobile devices, adolescents with friends have never been more instantaneous (Ito et al., 2009) because they can keep in touch easily. Self-presentation on social media will enable people to examine body image of the person that appear in the social media. This is further reinforced positively through postings on a profile made by people other than the user themselves to assert their identity (Walther et al., 2008) and the development of their social identity (Livingstone, 2008). Adolescents are susceptible to peer pressure and have a limited capacity for self-regulation posing a risk to them as they are on social media (O'Keeffe and Clarke-Pearson, 2011).

Social influences determine user behaviours on social media platforms where individuals tend to coordinate their behaviours to conform to social norms and mimicking (Zhou, 2011; Lewis et al., 2008; Cheung et al., 2015). Equal to the effects of thin-ideal media, peers who closely match the thin-ideal pose an equivalent risk of developing body dissatisfaction in women, because they are perceived to exhibit a more personally attainable ideal compared to models or celebrities (Carey et al., 2013; Halliwell et al., 2011). Apart from direct criticisms of thinness, conversations about thinness with peers, indirect competition for potential partners also affect and risk cultivating unfavourable norms (i.e. Alcohol consumption, sexual solicitation, bullying and tobacco advertisements) (Huang et al., 2014; Lawler and Nixon, 2011; Ferguson et al., 2014). According to Hofstede's cultural variables (Hofstede, 1984; Magnusson et al., 2008, Hofstede, 2001) the majority of the Asian countries are characterised by the following spectrum of the 5 dimensions: (1) high power distance, (2) collectivism, (3) femininity, (4) low uncertainty avoidance, and (5) short term orientation (Hofstede Insights, 2017; Schütte and Ciarlante, 2016). In conclusion, Asian culture depends more on personal sources of recommendations that emphasises on belonging to a social system that focuses on self-enhancement. The implications of this are that social media users are very image conscious and carefully craft their online persona, they are highly affected by peer influence and put a high weightage on word of mouth and recommendations from personal information sources (Goodrich and De Mooij, 2014).

H3: Friend influence has a significant impact towards body comparison on social media.

$\mathrm{H}_{4}$ : Friend influence has a significant impact towards body image.

\subsection{Impact of Social Media on Body Image}

Social media is a new communication landscape which employs mobile and web-based technologies to create highly interactive platforms where individuals and communities share, co-create, discuss, and modify user-generated content in real time (Kietzmann et al., 2011, Bizirgianni and Dionysopoulou, 2013). Living in the digital era, where youth are more reliant on technology than ever before, past research results showed that those more concerned with body image were prevalent in children who use social networking sites (Tiggemann and Slater, 2017; Tiggemann and Slater, 2013; Tiggemann and Slater, 2014). Past studies indicate that social media is a double-edged sword where it is a source of information for developing new skills (Ahn, 2011), and safe health practices (Hawn, 2017) but posited academic difficulties (Kirschner and Karpinski, 2010). Among other impacts, such as violence and sexual harassment (Haseeb, Abidin, Hye \& Hartani, 2018; Strasburger et al., 2010), which impacts both genders (de Vries et al., 2016). It is theorised that, social comparative information shared on social media platforms have a positive effect (upward comparison) because, it is a perfect platform for users to portray an ideal self-presentation. This can be done through the meticulous strategy in order to construct an online persona showcasing their most desirable traits (Vogel et al., 2014). Social media also provides quantitative and qualitative information about the person's social network, where a person with an active social network, who engages with other network members (comments and approval of content) is likely to be a target of upward comparison in terms of popularity, sociability or perceived social capital (Pahi, Shah, Ahmed \& Umrani, 2016; Kim and Lee, 2011, Vitak and Ellison, 2013). Studies have shown that, social media exposure does impact body image both positively and negatively. It depends on the type of online interaction; "likes" on social media boost a positive perception of body image but seeing other people's selfies or even posting one's selfies may led to negative perception of body image (Grogan, 2016, Chua and Chang, 2016, Tiidenberg, 2014).

Media-internalisation (a.k.a. thin-ideal internalisation) is the degree to which individuals adhere to social standards on physical appearance and set goals towards achieving those standards (Rodgers et al., 2015). It support of this etiological pathway, the introduction of mass-media in a non-Western culture also increases the effects of 
media-internalization (Becker et al., 2002, Bilukha and Utermohlen, 2002). The media-ideal internalisation and appearance comparison leads to the development of body dissatisfaction and self-objectification (Damiano et al., 2015, Dakanalis et al., 2015) where the children feel unsatisfied with their own body. These negative emotional experiences lead to body shame, appearance anxiety, and triggered dietary restraint through binge eating (Grabe et al., 2008, Dakanalis et al., 2015, Halliwell and Diedrichs, 2014). Based on Strasburger et al. (2010), these effects are heightened by the increase in media exposure - as seen in the increasing trend of adolescents' usage of the Internet. On the contrary, Agliata and Tantleff-Dunn (2004); Hayes and Tantleff-Dunn (2010) claimed that viewing appearance-related media decreases the standards of media-internalisation and depression.

$\mathrm{H}_{5}$ : Body comparison on social media has a significant impact towards body image.

\subsection{Children (Generation Z)}

Adolescents, as defined by Ito et al. (2009), are aged between 13 and 18 which happens to concurrently fall within the category of Generation Z (Gen Z). Gen Z are "digital natives born between the mid-90's and mid-00's, called as the Millennials holding $\$ 44$ billion buying power where all industries should definitely direct their attention and efforts towards understanding this rising demographic (Forbes Media LLC., 2017). Gen $Z$ value privacy and hence they have a preference towards anonymous social media platforms such as Snapchat or Instagram Story which do not leave permanent records on users (Forbes Media LLC., 2016). YouTube is also a big influence in their lives as they look to YouTubers as influencers. Gen Z also use YouTube as a means of gaining knowledge (Paige, 2017). It is important for the media to portray different images of body types in order to redefine standards of beauty. Furthermore, this stresses the importance of then having to monitor social media usage of adolescents as their exposure to such media images increases. Gen Z spends 74\% (Forbes Media LLC., 2017) of their free time with computers or on mobile devices. $66 \%$ of kids aged six to eleven use online gaming as a mode of entertainment, which has led to obesity tripling in the past four decades leading up to 2010 (Business Insider Inc., 2014).

\section{Method}

A non-probability sampling technique is employed for this study due to the time constraint and convenience of accessing the necessary target respondents (Flinders University, 2017). The issue with this method is that every unit of the population does not get an equal chance of participating in the investigation, hence, it is prone to systematic errors and sampling biases (Alvi, 2016). Specifically, the type of non-probability sampling technique used for the purpose of this study is snowball sampling which is goes by chain sampling (Alvi, 2016). This technique was beneficial for this study as the researcher had a limited number of friends that fell under the specific criteria. Hence it made the process act as a catalyst to speed up the data collection process. The drawback with implementing this technique was the sampling biases and systematic errors due to not having enough adolescents in particular age ranges or of specific demographics various groups were disregarded by the researcher due to errors of coverage. Due to the sensitivity of some of the questions asked, measurement errors may occur (Fricker, 2008). The criteria involved in snowball sampling for the purpose of this study are the respondent must be between the ages of 13 years old and 18 years old, and; they must currently reside in Malaysia.

\subsection{Sampling Frame and Sample Size Determination}

It is estimated, in Malaysia, that the percentage of the population between the age 13 years old and 18 years old is approximately $12.35 \%$ (United Nations, 2006) of the overall population at 32.2 million. The sample size of this study is 384 units according to the sampling suggestion by Krejcie and Morgan (1970). However, due to time constraints, only 282 were collected from the respondents of this study in the span of a week with the total of 73.44 percent of response rate.

\subsection{Questionnaire Design and Measurement and Scales}

The questionnaire for this research consists of six segments includes one dependent variable, three independent variables, one mediating variable, and demographic variable. Section One of the questionnaire consists of a filtered questions to meet the criteria with regards to the age group to be our targeted respondents, the respondents' rights, a brief description of the questionnaire, the researcher's contact details and the respondent's consent. Section Two consists of 10 demographic questions which are meant for all the purpose of descriptive analysis. Section Three to Seven consist of the main questions made up of 5-point Likert scale system which produce a common approach which is simple to understand, easy to analyse and it is capable of easily transforming ordinal data to a linear or interval scale (Johns, 2010, Treiblmaier and Filzmoser, 2011). The items used in this research were developed from the past literatures and were empirically tested for their reliability and consistency. The following are scales that have been incorporated and used in this study: 


\subsubsection{Adolescent Body Image Satisfaction Scale (ABISS)}

ABISS is a scale to measure adolescent body image satisfaction by determining the current body image satisfaction. The initial ABISS consisted of 32 items measuring various interpersonal aspects of body image that reflect how body image exists on a continuum of 'positive and healthy' to 'negative and unhealthy' (Leone et al., 2011). This research adopts a more recent version of this scale (Leone et al., 2011) that consists of 16 items.

\subsubsection{Rosenberg's Self-Esteem Scale (RSES)}

The RSES measures self-esteem through a 10-item scale which measures both positive and negative feelings about oneself (Rosenberg, 1965). This is a widely used instrument due to its high reliability $(\alpha=0.72)$, convergence and discriminant validity (Pugh, 2017, Al Nima et al., 2013). All scale items are measured using a 5-point Likert scale ranging from 1 (strongly agree) to 5 (strongly disagree) (Orth and Luciano, 2015) meanwhile scale items 3, 5, 8, 9 and 10 have been revised from a negative construct to a positive construct. The scale ranges from 0 to 30 where scores between 15 and 25 are considered normal while scores below 15 indicate low self-esteem (Rosenberg, 1965).

\subsubsection{Sociocultural Attitude Towards Appearance Questionnaire (SATAQ)}

SATAQ is a widely-used scale which measures the internalisation of personal ideals and social standards of appearance (Thompson et al., 2012, Schaefer et al., 2015). The detailed version of the scale is the scale assesses the internalisation of self-appearance ideas, friend influenced appearance pressures, family-influenced, appearance pressures and media influenced appearance pressures which demonstrate strong psychometric properties i.e. the reliability and validity of the instrument (Schaefer et al., 2017). The original scale had 40 items comprising of 16 internalizations and 24 pressures rated on a 5-point Likert scale (Schaefer et al., 2015, Schaefer et al., 2017). For the purpose of this study, only questions regarding to friend influence and media influence were adopted.

\section{Results}

Based on the $\mathrm{R}^{2}$, body image explains $55.5 \%$ of the independent variables (self-esteem and friend influence) as well as the mediating variables (body comparison on social media). Based on the standardised regression weights, self-esteem has a direct impact (.740) on body image. However, it poses an inverse impact (-.293) towards body comparison on social media. Friend influence has a direct impact towards both body comparisons on social media (.396) and body image (.110). Body comparison on social media has an inverse impact on body image (-.010). Initial PLS analysis reported that most of the items had acceptable factor loadings ( $>.40)$ which indicate that the items were statistically significant. The composite reliability (CR) of all variables were tested to have internal consistency $(>.70)$ where the first-order latent variable, Friend influence presented an AVE beyond the acceptable range $(.27<\mathrm{x}<.40)$ while Self-esteem falls within the acceptable range meaning that only self-esteem has a convergent validity. Based on the bootstrapping, the t-value > 1.960 (for 2-tailed), which is equivalent to $\mathrm{p}<0.05$; all hypothesis, from $\mathrm{H}_{1}$ to $\mathrm{H}_{4}$, are accepted. $\mathrm{H}_{5}$ was rejected due to its $\mathrm{t}$-value is beyond the acceptable range.

\section{Discussion}

This study concludes that $\mathrm{H}_{1}, \mathrm{H}_{2}, \mathrm{H}_{3}$ and $\mathrm{H}_{4}$ are significant and do really impact the body image among adolescences while only $\mathrm{H}_{5}$ is insignificant and do not really impact the body image among adolescences. $\mathrm{H}_{1}$ is supported where self-esteem impacts body comparison on social media. This finding supports majority of the findings from other research in the past (Valkenburg and Piotrowski, 2017, Woods and Scott, 2016, Sampasa-Kanyinga and Lewis, 2015). However, the $\mathrm{H}_{1}$ is negatively correlated. This is in line with researches in the past where low self-esteem has been associated with a higher tendency to compare oneself with others who are better than them that leads to negative body image (Perloff, 2014). Interestingly, the study also identified that there is a significance relationship between the direct impact of self-esteem towards positive perception of one's body image without the mediation of social media, i.e. $\mathrm{H}_{2}$ which has been likely that such a phenomenon exists as stated in the research due to its findings having been the same over a period of time by different studies (Grogan, 2016). On the other hand, the study found that the $\mathrm{H}_{3}$ is supported where friend do influence the body comparison on social media. This interesting finding supports most past findings where positive friend influence would have positively boosts perception of body image (Carey et al., 2013, Halliwell et al., 2011). Study also shows $\mathrm{H}_{4}$ where friend influence was identified to give direct impact on body image. This could be due to the richness of this form of face-to-face communication which involves gestures, gaze, voice and other body language cues that could be used to better express oneself (Reich et al., 2012). Hence, social support (positive affirmations and supportiveness) of friends could be better communicated since in a collectivist culture (Barak et al., 2016).

On the other hand, the $\mathrm{H}_{5}$ where social media which was hypothesised as to give impact on body image is sadly not supported. This could be due to the ability of adolescents to differentiate between what is realistic and what is not 
(Williams and Page, 2011). Similarly, the study conducted by Ferguson et al. (2014), where social media exposure did not impact body image, even though there is indication of body comparison within social media platforms amongst peers. This could be possible within the digital context because the sense of assimilation is not as great without the physical presence of people as a community. Another reason why social media does not impact body image could be because adolescents use the online environment to build and maintain relationships rather than as a medium to compare where upward and downward comparisons occur (Ellison, 2007, Lampe et al., 2007, Christofides et al., 2009, Ellison et al., 2014).

\section{Theoretical and Managerial Implications}

Social comparison theory is a psychological theory that explains how an individual measures their social and personal worth through self-evaluation and evaluation through comparison with others across a variety of dimensions (Suls and Wheeler, 2011). In an advertising context, this theory can help corporations and marketers to better understand consumer behaviour and how the content of advertising impacts consumers. Vygotsky's sociocultural theory is an emerging theory in psychology that argues the case for an individual's cognitive function being organised, through a mediated process, by cultural artefacts, activities and concepts. This theory shows how the culture in which an individual exists shapes the behaviour of the community such as social norms and beauty standards. It is better to select brand ambassadors that consumers would be able to better relate to and find similarity with. Within the context of this study, Signalling theory is applied in the context of advertising and consumer behaviour where, media portrayal and friend influence play a part in signalling an individual of appearance and standard of beauty as well as behaviour on social media. Advertisers and companies could use the data and findings within this study to better understand their role in shaping the society of the future. Advertisers and companies will understand how appearance-based media still has an impact towards the intrinsic growth of adolescents. They should act morally ethical by selecting appropriate models and influencers as brand ambassadors that the adolescents could resonate in terms of personality and outward appearance. This will enable adolescents to boost self-esteem a parallel comparison which boosts intrinsic growth. This could concurrently boost sales when adolescents feel like they can relate to the brand ambassador.

This study provides a better insight for the government on the importance of regulation of advertisements. Understanding how social media, self-esteem, friends and appearance-specific media impacts body image and its detrimental effects such as suicide, obesity, poor academic performance among other plausible negative impacts are crucial for us in protecting the adolescence. It should be the government's utmost importance to screen media for the masses before it is put out for the general public to view. This study could also be beneficial for the society at large to create a more socially supportive environment for adolescents to communicate and help them grow their mind-set on the acceptable and realistic standards of beauty. Adolescences also need to be educated on the reality that "Beauty is the property of every human and each of them a beautifully created". Representation on social media may be exaggerated and adolescents may not take it at face value. Friends, family and the society should educate and be educated on how beauty exists beyond what is shown on the media. It is because the media mostly portrays being thin is beautiful. Society should emphasise more on a healthy way of living for physical and mental health benefits. This study also contributes to the existing knowledge on the mediating role of social media. This includes what variables impact social media behaviour and how social media acts as a mechanism and platform of communication. It also adds knowledge to how powerful social media in giving impacts to body image which includes the culture and social constructs.

\section{Limitations and Suggestions for Future Research}

One of the limitations to this study is the small sample size compared to the original population. The sample of this study is students between the ages of 13 to 18 years old. According to the (United Nations, 2006), the total number of students within this age range in Malaysia amounts to a tenth of the original population of 30 million people, which means there are approximately 3 million students within this sample age range in Malaysia. According to Krejcie and Morgan (1970), the sample size for a population of 1 million and above, should be approximately 384. Therefore, this study clearly below the expected norm for such a population to be confidently generalised to the whole student population of Malaysia. Besides that, there could be a sampling bias as well, as the data was collected via snowball sampling. With the use of snowball sampling, the respondents to the study might only consist of cooperative individuals from the researcher's personal network (Čandrlić, 2013). It has been shown by Laakasuo et al. (2017), that people tend to surround themselves with others who are more similar to them than not. Therefore, individuals from the researcher's network may pass the survey onto their circle of friends who have, or might have, highly similar traits to them. Another limitation is that the sample might have not responded to the questionnaire 
seriously, as it was only passed from the previous individual, and without knowing the background of the researcher or the study (Baltar and Brunet, 2012). Other than that is the effect of the environmental factors on the data. Using snowball sampling, the researcher has limited control over the environment in which the participant is answering the questionnaire in. It is stated by Harrison and McLaughlin (1993) that the cognitive processes of participants differ across different environments. Due to the lack of control over the environment in which individuals answer the questionnaire, their response might not be an accurate reflection of their personal opinions as the context of the answers. Lastly, due to the need of samples that vary in between the age of 13 to 18 , respondents might not all understand the questions in the same way, and they might be interpreting them differently. This is because the level of understanding the questions may not be similar to all respondents due to the differences in understanding the language, and different age level (Bishop, 2014). Thus, further explanation by the researcher is needed as assistance during the survey.

Future research should be conducted through a qualitative research design, to get in depth- understanding. Furthermore, future research could also focus on employing a different sampling methods in recruiting samples such as stratified sampling to eliminate possible biasness and generate a more normally distributed result. It is also highly recommended to future researchers to inculcate the differences of ethnic and cultures in predicting this issue. In a multicultural society like Malaysia, it is good if a comprehensive comparative study could be conducted to see the nature of this issue among different cultures and societies of the country.

\section{References}

Agliata, D., \& Tantleff, D. S. (2004). The impact of media exposure on males' body image. Journal of Social and Clinical Psychology, 23, 7-22. https://doi.org/10.1521/jscp.23.1.7.26988

Ahn, J. (2011). The effect of social network sites on adolescents' social and academic development: Current theories and controversies. Journal of the Association for Information Science and Technology, 62, 1435-1445.

Ahn, Y. Y., Han, S., Kwak, H., Moon, S., \& Jeong, H. (2007). Analysis of topological characteristics of huge online social networking services. Proceedings of the 16th international conference on World Wide Web (pp. 835-844.). ACM. https://doi.org/10.1145/1242572.1242685

AL Nima, A., Rosenberg, P., Archer, T., \& Garcia, D. (2013). Anxiety, affect, self-esteem, and stress: mediation and moderation effects on depression. PLoS One, 8, e73265. https://doi.org/10.1371/journal.pone.0073265

Alvi, M. H. (2016). A Manual for Selecting Sampling Techniques in Research.

Apaolaza, V., Hartmann, P., Medina, E., Barrutia, J. M., \& Echebarria, C. (2013). The relationship between socializing on the Spanish online networking site Tuenti and teenagers' subjective wellbeing: The roles of self-esteem and loneliness. Computers in Human Behavior, 29, 1282-1289.

Bachrach, M., \& Gambetta, D. (2001). Trust in signs. Trust in Society, 2, 148-184.

Bagozzi, R. P., \& Lee, K.-H. (2002). Multiple routes for social influence: The role of compliance, internalization, and social identity. Social Psychology Quarterly, 226-247. https://doi.org/10.2307/3090121

Balistreri, E., Busch-Rossnagel, N. A., \& Geisinger, K. F. (1995). Development and preliminary validation of the Ego Identity Process Questionnaire. Journal of Adolescence, 18, 179-192.

Baltar, F., \& Brunnett, I. (2012). Social research 2.0: virtual snowball sampling method using Facebook. Internet Research, 22, 57-74. https://doi.org/10.1108/10662241211199960

Barak, M. E. M., Findler, L., \& Wind, L. H. (2016). Diversity, inclusion, and commitment in organizations: International empirical explorations. Journal of Behavioral and Applied Management, 2.

Becker, A. E., Burnwell, R. A., Herzog, D. B., Hamburg, P., \& Gilmann S. E. (2002). Eating behaviours and attitudes following prolonged exposure to television among ethnic Fijian adolescent girls. The British Journal of Psychiatry, 180, 509-514. https://doi.org/10.1192/bjp.180.6.509

Benton, C., \& Karazkia, B. T. (2015). The effect of thin and muscular images on women's body satisfaction. Body Image, 13, 22-27. https://doi.org/10.1016/j.bodyim.2014.11.001

Best, P., Manktelow, R., \& Taylor, B. (2014). Online communication, social media and adolescent wellbeing: A systematic narrative review. Children and Youth Services Review, 41, 27-36.

Bilukha, O. O., \& Utermohlen, V. (2002). Internalization of Western standards of appearance, body dissatisfaction and dieting in urban educated Ukrainian females. European Eating Disorders Review, 10, 120-137. 
Bishop, D. (2014). Uncommon Understanding (Classic Edition): Development and disorders of language comprehension in children. Psychology Press. https://doi.org/10.4324/9780203381472

Bizirgianni, I., \& Dionysopoulou, P. (2013). The influence of tourist trends of youth tourism through social media (SM) \& information and communication technologies (ICTs). Procedia-Social and Behavioral Sciences, 73, 652-660. https://doi.org/10.1016/j.sbspro.2013.02.102

Boisvert, J. A., \& Harrel, W. A. (2010). Homosexuality as a risk factor for eating disorder symptomatology in men. The Journal of Men's Studies, 17, 210-225. https://doi.org/10.3149/jms.1703.210

Burgo, J. (2016). The Narcissist You Know: Defending Yourself Against Extreme Narcissists in an All-about-me Age. Simon and Schuster.

Čandrilic, G. (2013). Cloud Computing - Types of Cloud. Retrieved from http://www.globaldots.com/cloud-computing-types-of-cloud/

Carey, R. N., Donaghue, N., \& Broderik, P. (2013). Peer culture and body image concern among Australian adolescent girls: A hierarchical linear modelling analysis. Sex Roles, 69, 250-263.

Cash, T. F., \& Pruzinsky, T. (2004). Body image: A handbook of theory, research, and clinical practice. The Guilford Press.

Chang, C.-C., Hung, S.-W., Cheng, M.-J., \& Wu, C.-Y. (2015). Exploring the intention to continue using social networking sites: The case of Facebook. Technological Forecasting and Social Change, 95, 48-56.

Cheung, C., Lee, Z. W., \& Chan, T. K. (2015). Self-disclosure in social networking sites: the role of perceived cost, perceived benefits and social influence. Internet Research, 25, 279-299.

Christofides, E., Muise, A., \& Desmarais, S. (2009). Information disclosure and control on Facebook: are they two sides of the same coin or two different processes?. CyberPsychology \& Behavior, 12, 341-345.

Chua, T. H. H., \& Chang, L. (2016). Follow me and like my beautiful selfies: Singapore teenage girls' engagement in self-presentation and peer comparison on social media. Computers in Human Behavior, 55, 190-197.

Croll, J. (2005). Body Image and Adolescents. The Journal of Social Psychology.

Cronk, L. (2005). The application of animal signaling theory to human phenomena: some thoughts and clarifications. Social Science Information, 44, 603-620. https://doi.org/10.1177/0539018405058203

Dakanalis, A., Carra, G., Calogero, R., Fida, R., Clerici, M., Zanetti, M. A., \& Riva, G. (2015). The developmental effects of media-ideal internalization and self-objectification processes on adolescents' negative body-feelings, dietary restraint, and binge eating. European child \& Adolescent Psychiatry, 24, 997-1010.

Damiano, S. R., Paxton, S. J., Wertheim, E. H., Mclean, S. A., \& Gregg, K. J. (2015). Dietary restraint of 5-year-old girls: Associations with internalization of the thin ideal and maternal, media, and peer influences. International Journal of Eating Disorders, 48, 1166-1169. https://doi.org/10.1002/eat.22432

Davenport, S. W., Bergman, S. M., Bergman, J. Z., \& Fearrington, M. E. (2014). Twitter versus Facebook: Exploring the role of narcissism in the motives and usage of different social media platforms. Computers in Human Behavior, 32, 212-220. https://doi.org/10.1016/j.chb.2013.12.011

De Vries, D. A., Peter, J., De Graaf, H., \& Nikken, P. (2016). Adolescents' social network site use, peer appearance-related feedback, and body dissatisfaction: testing a mediation model. Journal of Youth and Adolescence, 45, 211-224. https://doi.org/10.1007/s10964-015-0266-4

Dijkstra, P., Kuyper, H., Van Der Werf, G., Buunk, A. P., \& Van Der Zee, Y. G. (2008). Social comparison in the classroom: A review. Review of Educational Research, 78, 828-879.

Donath, J. (2007). Signals in social supernets. Journal of Computer-Mediated Communication, 13, $231-251$.

Ellison, N. B. (2007). Social network sites: Definition, history, and scholarship. Journal of Computer-Mediated Communication, 13, 210-230. https://doi.org/10.1111/j.1083-6101.2007.00393.x

Ellison, N. B., Vitak, J., Gray, R., \& Lampe, C. (2014). Cultivating social resources on social network sites: Facebook relationship maintenance behaviors and their role in social capital processes. Journal of Computer-Mediated Communication, 19, 855-870. https://doi.org/10.1111/jcc4.12078

Ferguson, C. J., Munoz, M. E., Garza, A., \& Galindo, M. (2014). Concurrent and prospective analyses of peer, television and social media influences on body dissatisfaction, eating disorder symptoms and life satisfaction in 
adolescent girls. Journal of Youth and Adolescence, 43, 1-14.

Festinger, L. (1954). A theory of social comparison processes. Human Relations, 7, 117-140.

Fraser, B. P., \& Brown, W. J. (2002). Media, celebrities, and social influence: Identification with Elvis Presley. Mass Communication \& Society, 5, 183-206. https://doi.org/10.1207/S15327825MCS0502_5

Fricker, R. D. (2008). Sampling methods for web and e-mail surveys. The SAGE handbook of online research methods (pp.195-216). https://doi.org/10.4135/9780857020055.n11

Germain, M.-L. (2017). Introduction. Narcissism at Work. Springer. https://doi.org/10.1007/978-3-319-60330-8

Goodrich, K., \& De Mooij, M. (2014). How 'social'are social media? A cross-cultural comparison of online and offline purchase decision influences. Journal of Marketing Communications, 20, 103-116.

Grabe, S., Ward, L. M., \& Hyde, J. S. (2008). The role of the media in body image concerns among women: a meta-analysis of experimental and correlational studies. Psychological Bulletin, 134, 460.

Grammas, D. L., \& Schwartz, J. P. (2009). Internalization of messages from society and perfectionism as predictors of male body image. Body Image, 6, 31-36. https://doi.org/10.1016/j.bodyim.2008.10.002

Grogan, S. (2016). Body image: Understanding body dissatisfaction in men, women and children. Taylor \& Francis.

Haboush, A., Warren, C. S., \& Benuto, L. (2012). Beauty, ethnicity, and age: Does internalization of mainstream media ideals influence attitudes towards older adults?. Sex Roles, 66, 668-676.

Halliwell, E., Malson, H., \& Tischner, I. (2011). Are contemporary media images which seem to display women as sexually empowered actually harmful to women?. Psychology of Women Quarterly, 35, 38-45.

Halliwell, E.. \& Diedrichs, P. C. (2014). Testing a dissonance body image intervention among young girls. Health Psychology, 33, 201. https://doi.org/10.1037/a0032585

Han, Y. J., Nunes, J. C., \& Dreze, X. (2010). Signaling status with luxury goods: The role of brand prominence. Journal of Marketing, 74, 15-30. https://doi.org/10.1509/jmkg.74.4.015

Hanus, M. D., \& Fox, J. (2015). Assessing the effects of gamification in the classroom: A longitudinal study on intrinsic motivation, social comparison, satisfaction, effort, and academic performance. Computers \& Education, 80, 152-161. https://doi.org/10.1016/j.compedu.2014.08.019

Harrison, D. A., \& McLaughlin, M. E. (1993). Cognitive processes in self-report responses: tests of item context effects in work attitude measures. Journal of Applied Psychology, 78, 129.

Haseeb, M., Abidin, I. S. Z., Hye, Q. M. A., \& Hartani, N. H. (2018). The Impact of Renewable Energy on Economic Well-Being of Malaysia: Fresh Evidence from Auto Regressive Distributed Lag Bound Testing Approach. International Journal of Energy Economics and Policy, 9(1), 269-275.

Hawn, C. (2017). Take two aspirin and tweet me in the morning: how Twitter, Facebook, and other social media are reshaping health care. Health Affairs.

Hayes, S., \& Tantleff-Dunn, S. (2010). Am I too fat to be a princess? Examining the effects of popular children's media on young girls' body image. British Journal of Developmental Psychology, 28, 413-426.

Heatherton, T. F., \& Polivy, J. (1991). Development and validation of a scale for measuring state self-esteem. Journal of Personality and Social Psychology, 60, 895. https://doi.org/10.1037//0022-3514.60.6.895

Hoffman, A. O., \& Broekhuize, T. L. (2009). Susceptibility to and impact of interpersonal influence in an investment context. Journal of the Academy of Marketing Science, 37, 488-503. https://doi.org/10.1007/s11747-008-0128-7

Hofstede, G. (1984). Culture's consequences: International differences in work-related values. Sage.

Hofstede, G. (2001). Culture's consequences: Comparing values, behaviors, institutions, and organizations across cultures. Thousand Oaks, CA: Sage.

Hoorens, V., \& Damme, C. V. (2012). What do people infer from social comparisons? Bridges between social comparison and person perception. Social and Personality Psychology Compass, 6, 607-618.

Huang, G. C., Unger, J. B., Soto, D., Fujimoto, K., Pentz, M. A., Jordan-Marsh, M., \& Valente, T. W. (2014). Peer influences: the impact of online and offline friendship networks on adolescent smoking and alcohol use. Journal of Adolescent Health, 54, 508-514. https://doi.org/10.1016/j.jadohealth.2013.07.001

Hye, Q. M. A., \& Lau, W. Y. (2018). Does Financial and Trade liberalization Drive Private Investment in Pakistan?. 
Asian Journal of Economics and Empirical Research, 5(1), 112-120.

Idrees, R. Q., Shapiee, R., Ahamat, H., \& Hanwei, L. (2018). How Logistics Investment Arrangement is a Key Concern to China-Pakistan Economic Corridor (CPEC)? A Legal and Policy Analysis of CPEC Logistics Investment Model and Future Challenges for Pakistan. International Journal of Asian Social Science, 8(11), 1059-1067. https://doi.org/10.18488/journal.1.2018.811.1059.1067

Inc., B. I. (2015). Millennials Are Old News - Here's Everything You Should Know About Generation Z. Retrieved 29 October 2017, from http://www.businessinsider.com/generation-z-spending-habits-2014-6/?IR=T

Inchamnan, W. (2018). Therapeutic Strategy in Gamification and Game Based Learning for Elderly People in Thailand. Humanities \& Social Sciences Reviews, 6(1), 44-52. https://doi.org/10.18510/hssr.2018.618

Ingolfsdottir, G., Asgeirsdottir, B. B., Gunnarsdotti, T., \& Bjornsson, A. S. (2014). Changes in body image and dieting among 16-19-year-old Icelandic students from 2000 to 2010. Body Image, 11, 364-369.

Insights, H. (2017). Country Comparison. Retrieved 1 December 2017, from https://www.hofstede-insights.com/country-comparison/malaysia/

Inusah, N. (2018). Toda-yamamoto granger no-causality analysis of stock market growth and economic growth in ghana. Journal of Accounting, Business and Finance Research, 3(1), 36-46.

Islam, S., Nahar, T. N., Begum, J., Khatun, M., \& Hossain, M. I. (2018). Marketing and Financial Analysis of Milk Production-A Value Chain Perspective. Asian Development Policy Review, 6(1), 32-40.

Ismail, I. B., Sabran, R., \& Ariffin, Y. B. M. (2018). Conceptualising Communication Media and Farmer's Reaction in Problem Solving. Humanities \& Social Sciences Reviews, 6(1), 01-07. https://doi.org/10.18510/hssr.2018.611

Ito, M., Baumer, S., Bittanti, M., Cody, R., Stephenson, B. H., Horsts, H. A., ... Pascoe, C. (2009). Hanging out, messing around, and geeking out: Kids living and learning with new media. MIT press.

Jermsittiparsert, K, Sriyakul, T., \& Pamornmast, C. (2012). An Empirical Proposal on Power, Knowledge and Truth of Correlations among the Minimum Wages, Foreign Direct Investment in the Industrial Sector and Export. Social and Management Research Journal, 9(1), 21-33. https://doi.org/10.24191/smrj.v9i1.5210

Jermsittiparsert, K, Sriyakul, T., \& Pamornmast, C. (2012). An Empirical Discourse Analysis on Correlations between the Minimum Wages and Domestic Private Investment. Journal of US-China Public Administration, 9(7), 768-774.

Jermsittiparsert, K, Sriyakul, T., \& Pamornmast, C. (2012). The "Populism" Policy and Building/Diminishing Economic "Inequality" and "Unfairness": Empirical Suggestion on Pork-Barrel in Thailand's Rice Trading Business. Public Policy and Administration Research, 2(7), 21-31. https://doi.org/10.2139/ssrn.1994431

Jin, S.-A. A., \& Phua, J. (2014). Following celebrities' tweets about brands: The impact of Twitter-based electronic word-of-mouth on consumers' source credibility perception, buying intention, and social identification with celebrities. Journal of Advertising, 43, 181-195. https://doi.org/10.1080/00913367.2013.827606

Johns, R. (2010). Likert items and scales.

Kaminski, M. M. (2010). Games prisoners play: The tragicomic worlds of Polish prison. Princeton University Press.

Kantanista, A., Osinski, W., Borowiec, J., Tomzczak, M., \& Krol-Zielinska, M. (2015). Body image, BMI, and physical activity in girls and boys aged 14-16 years. Body Image, 15, 40-43.

Kastanakis, M. N., \& Balabanis, G. (2014). Explaining variation in conspicuous luxury consumption: An individual differences' perspective. Journal of Business Research, 67, 2147-2154.

Kietzmann, J. H., Hermkens, K., Mccarthy, I. P., \& Silvestre, B. S. (2011). Social media? Get serious! Understanding the functional building blocks of social media. Business Horizons, 54, 241-251.

Kim, J., \& Lee, J.-E. R. (2011). The Facebook paths to happiness: Effects of the number of Facebook friends and self-presentation on subjective well-being. CyberPsychology, Behavior, and Social Networking, 14, 359-364.

Kirschner, P. A., \& Karpinski, A. C. (2010). Facebook ${ }^{\circledR}$ and academic performance. Computers in Human Behavior, 26, 1237-1245. https://doi.org/10.1016/j.chb.2010.03.024

Koyuncu, M., Tok, S., Canpolat, A. M., \& Cattikas, F. (2010). Body image satisfaction and dissatisfaction, social physique anxiety, self-esteem, and body fat ratio in female exercisers and nonexercisers. Social Behavior and Personality: An International Journal, 38, 561-570. https://doi.org/10.2224/sbp.2010.38.4.561 
Krejcie, R. V., \& Morgan, D. W. (1970). Determining sample size for research activities. Educational and Psychological Measurement, 30, 607-610. https://doi.org/10.1177/001316447003000308

Laakasuo, M., Rotkirch, A., Berg, V., \& Jokela, M. (2017). The Company You Keep: Personality and Friendship Characteristics. Social Psychological and Personality Science, 8, 66-73.

Lampe, C. A., Ellison, N., \& Steinfiled, C. (2007). A familiar face (book): profile elements as signals in an online social network. Proceedings of the SIGCHI conference on Human factors in computing systems (pp. 435-444). ACM. https://doi.org/10.1145/1240624.1240695

Lawler, M., \& Nixon, E. (2011). Body dissatisfaction among adolescent boys and girls: the effects of body mass, peer appearance culture and internalization of appearance ideals. Journal of Youth and Adolescence, 40, 59-71.

Leeson, P. T. (2009). The invisible hook: the hidden economics of pirates. Princeton University Press.

Leone, J. E., Fetro, J. V., Kittleson, M., Welshimer, K. J., Partridge, J. A., \& Robertson, S. L. (2011). Predictors of adolescent male body image dissatisfaction: Implications for negative health practices and consequences for school health from a regionally representative sample. Journal of School Health, 81, 174-184.

Lewis, K., Kaufman, J., \& Christakis, N. (2008). The taste for privacy: An analysis of college student privacy settings in an online social network. Journal of Computer-Mediated Communication, 14, 79-100.

Livingstone, S. (2008). Taking risky opportunities in youthful content creation: teenagers' use of social networking sites for intimacy, privacy and self-expression. New Media \& Society, 10, 393-411.

LLC., F. M. (2016). Get Ready for Generation Z. Retrieved 4 November 2017, from https://www.forbes.com/sites/causeintegration/2016/11/28/get-ready-for-generation-z/\#3ccce97d2204

LLC., F. M. (2017). How To Protect Data Privacy Of Connected Cars As Their Popularity Accelerates. Retrieved 29 October 2017 ,

from https://www.forbes.com/sites/ibm/2017/01/11/how-to-protect-data-privacy-of-connected-cars-as-their-popularit $\mathrm{y}$-accelerates/\#c65c5e 55e957

Magee, J. C., \& Smith, P. K. (2013). The social distance theory of power. Personality and Social Psychology Review, 17, 158-186. https://doi.org/10.1177/1088868312472732

Magnusson, P., Wilson, R. T., Zdravkovic, S., Xin Zhou, J., \& Westjohn, S. A. (2008). Breaking through the cultural clutter: a comparative assessment of multiple cultural and institutional frameworks. International Marketing Review, 25, 183-201. https://doi.org/10.1108/02651330810866272

Malaysia, D. O. S. (2017). Demographic Statistics Third Quarter (Q3), Malaysia. Retrieved 26 November 2017, from

https://www.dosm.gov.my/v1/index.php?r=column/cthemeByCat\&cat=430\&bul_id=MFpnNGw4RnZmRnNKe C80Q25DZUgzZz09\&menu_id=L0pheU43NWJwRWVSZklWdzQ4TlhUUT09

Meier, E. P., \& Gray, J. (2014). Facebook photo activity associated with body image disturbance in adolescent girls. Cyberpsychology, Behavior, and Social Networking, 17, 199-206. https://doi.org/10.1089/cyber.2013.0305

Morrison, T. G., Kalin, R., \& Morrison, M. A. (2004). Body-image evaluation and body-image investment among adolescents: A test of sociocultural and social comparison theories. Adolescence, 39, 571.

Mulgrew, K. E., Volcevski-Kostas, D., \& Rendell P. G. (2014). The effect of music video clips on adolescent boys' body image, mood, and schema activation. Journal of Youth and Adolescence, 43, 92-103.

Nations, U. (2006). Population by single years of age, sex, sex ratios and percentage: each census, 1985-2003.

Neira, B., Corey, J., \& Barber, B. L. (2014). Social networking site use: Linked to adolescents' social self-concept, self-esteem, and depressed mood. Australian Journal of Psychology, 66, 56-64.

O'Keeffe, G. S., \& Clarke-Pearson, K. (2011). The impact of social media on children, adolescents, and families. Pediatrics, 127, 800-804. https://doi.org/10.1542/peds.2011-0054

Orth, U., \& Luciono, E. C. (2015). Self-esteem, narcissism, and stressful life events: Testing for selection and socialization. Journal of Personality and Social Psychology, 109, 707. https://doi.org/10.1037/pspp0000049

Pahi, M. H., Shah, S. M. M., Ahmed, U., \& Umrani, W. A. (2016). Investigating the Issue of Nurse Job Satisfaction: Role of Esprit De Corps, Task Significance, Self-Efficacy and Resilience: A Case Study. International Journal of Academic Research in Business and Social Sciences, 6(4), 339-355. 
Paige, A. (2017). 11 Characteristics of Generation Z. Retrieved 4 November 2017 from https://www.yahoo.com/lifestyle/11-characteristics-generation-z-121000292.html

Perloff, R. M. (2014). Social media effects on young women's body image concerns: Theoretical perspectives and an agenda for research. Sex Roles, 71, 363-377. https://doi.org/10.1007/s11199-014-0384-6

Petrie, T. A., Greenleaf, C., \& Martin, S. (2010). Biopsychosocial and physical correlates of middle school boys' and girls' body satisfaction. Sex Roles, 63, 631-644. https://doi.org/10.1007/s11199-010-9872-5

Phillips, K. A. (2005). The broken mirror: understanding and treating body dysmorphic disorder. Oxford University Press, USA.

Pugh, S. (2017). Investigating the relationship between smartphone addiction, social anxiety, self-esteem, age \& gender.

Pyrooz, D. C., \& Densley, J. A. (2016). Selection into street gangs: Signaling theory, gang membership, and criminal offending. Journal of Research in Crime and Delinquency, 53, 447-481.

Rafindadi, A. A., \& Kondo, K. A. (2018). Public Finance and Rural Development in Nigeria: Empirical Evidence from the Structural Equation Modeling. Asian Economic and Financial Review, 8(11), 1313-1339.

Rauf, A. L. A. (2016). Financial management practices in small and medium sized enterprises: Empirical evidence from the district of Ampara in Sri Lanka. International Journal of Economics, Business and Management Studies, 3(3), 117-126.

Reich, S. M., Subrahmanyam, K., \& Espinoza, G. (2012). Friending, IMing, and hanging out face-to-face: overlap in adolescents' online and offline social networks. Developmental Psychology, 48, 356.

Robinson, J. P., Shaver, P. R., \& Wrightsman, L. S. (2013). Measures of Personality and Social Psychological Attitudes: Measures of Social Psychological Attitudes. Academic Press.

Rodgers, R. F., Mc Lean, S. A., \& Paxton, S. J. (2015). Longitudinal relationships among internalization of the media ideal, peer social comparison, and body dissatisfaction: Implications for the tripartite influence model. Developmental Psychology, 51, 706. https://doi.org/10.1037/dev0000013

Rosernberg, M. (1965). Society and the adolescent self-image. Princeton University Press.

Rosli, A., \& Siong, T. I. (2018). Determinants of Customers Satisfaction Towards Services Provided by Agencies in Urban Transformation Centre (UTC). International Journal of Economics, Business and Management Studies, 5(1), 9-15. https://doi.org/10.20448/802.51.9.15

Sampasa-Kanyinga, H., \& Lewis, R. F. (2015). Frequent use of social networking sites is associated with poor psychological functioning among children and adolescents. Cyberpsychology, Behavior, and Social Networking, 18, 380-385. https://doi.org/10.1089/cyber.2015.0055

Schaefer, L. M., Burke, N. L., Thompson, J. K., Dedrick, R. F., Heinberg, L. J., Calogero, R. M., ...Kelly, M. (2015). Development and validation of the Sociocultural Attitudes Towards Appearance Questionnaire-4 (SATAQ-4). Psychological Assessment, 27, 54.

Schaefer, L. M., Harriger, J. A., Heinberg, L. J., Soderberg, T., \& Kevin Thompson, J. (2017). Development and validation of the sociocultural attitudes towards appearance questionnaire-4-revised (SATAQ-4R). International Journal of Eating Disorders, 50, 104-117. https://doi.org/10.1002/eat.22590

Schutte, H., \& Ciarlante, D. (2016). Consumer behaviour in Asia. Springer.

Shukla, P., \& Banerjee, M. (2014). The direct and interactive effects of store-level promotions on impulse purchase: Moderating impact of category familiarity and normative influences. Journal of Consumer Behaviour, 13, 242-250. https://doi.org/10.1002/cb.1461

Simons-Morton, B. G., \& Farhat, T. (2010). Recent findings on peer group influences on adolescent smoking. The Journal of Primary Prevention, 31, 191-208. https://doi.org/10.1007/s10935-010-0220-x

Singh, D., Dixson, B. J., Jessop, T. S., Morgan, B., \& Dixson, A. F. (2010). Cross-cultural consensus for waist-hip ratio and women's attractiveness. Evolution and Human Behavior, 31, 176-181.

Strasburger, V. C., Jordan, A. B., \& Donnerstein, E. (2010). Health effects of media on children and adolescents. Pediatrics, 125, 756-767. https://doi.org/10.1542/peds.2009-2563

Suls, J., \& Wheeler, L. (2011). Social Comparison Theory. Handbook of Theories of Social Psychology (Vol. 1, p. 
460). https://doi.org/10.4135/9781446249215.n23

Swami, V., Frederick, D. A., Aavik, T., Alcalay, L., Allik, J., Anderson, D., ... Cunningham, J. (2010). The attractive female body weight and female body dissatisfaction in 26 countries across 10 world regions: Results of the International Body Project I. Personality and Social Psychology Bulletin, 36, 309-325.

Thompson, J. K., Schaefer, L., \& Menzel, J. (2012). Internalization of thin-ideal and muscular-ideal. Encyclopedia of body image and human appearance. Elsevier. https://doi.org/10.1016/B978-0-12-384925-0.00079-1

Tiggemann, M., \& Slater, A, A. (2014). NetTweens: The Internet and body image concerns in preteenage girls. The Journal of Early Adolescence, 34, 606-620. https://doi.org/10.1177/0272431613501083

Tiggemann, M., \& Slater, A, A. (2017). Facebook and body image concern in adolescent girls: A prospective study. International Journal of Eating Disorders, 50, 80-83. https://doi.org/10.1002/eat.22640

Tiggemann, M., \& Slater, A. (2013). NetGirls: The Internet, Facebook, and body image concern in adolescent girls. International Journal of Eating Disorders, 46, 630-633. https://doi.org/10.1002/eat.22141

Treiblmaier, H., \& Filzmoser, P. (2011). Benefits from using continuous rating scales in online survey research.

Tylka, T. L., \& Sabik, N. J. (2010). Integrating social comparison theory and self-esteem within objectification theory to predict women's disordered eating. Sex Roles, 63, 18-31. https://doi.org/10.1007/s11199-010-9785-3

University, F. (2017). Sampling.

Valkenburg, P. M., \& Piotrowski, J. T. (2017). Plugged in: How media attract and affect youth. Yale University Press. https://doi.org/10.12987/yale/9780300218879.001.0001

Van Rooy, D., Wood, I., \& Tran, E. (2016). Modelling the Emergence of Shared Attitudes from Group Dynamics Using an Agent-Based Model of Social Comparison Theory. Systems Research and Behavioral Science, 33, 188-204. https://doi.org/10.1002/sres.2321

Vilhjalmsson, R., Kristjansdottir, G., \& Ward, D. S. (2012). Bodily deviations and body image in adolescence. Youth \& Society, 44, 366-384. https://doi.org/10.1177/0044118X11402850

Vitak, J., \& Ellison, N. B. (2013). 'There'sa network out there you might as well tap': Exploring the benefits of and barriers to exchanging informational and support-based resources on Facebook. New Media \& Society, 15, 243-259. https://doi.org/10.1177/1461444812451566

Voelker, D. K., Reel, J. J., \& Greenleaf, C. (2015). Weight status and body image perceptions in adolescents: current perspectives. Adolescent Health, Medicine and Therapeutics, 6, 149. https://doi.org/10.2147/AHMT.S68344

Vogel, E. A., Rose, J. P., Roberts, L. R., \& Eckles, K. (2014). Social comparison, social media, and self-esteem. Psychology of Popular Media Culture, 3, 206. https://doi.org/10.1037/ppm0000047

Walther, J. B., Van Der Heidi, B., Kim, S. Y., Westerman, D., \& Tong, S. T. (2008). The role of friends' appearance and behavior on evaluations of individuals on Facebook: Are we known by the company we keep? Human Communication Research, 34, 28-49. https://doi.org/10.1111/j.1468-2958.2007.00312.x

Wangqvist, M., \& Frisen, A. (2013). Swedish 18-year-olds' identity formation: Associations with feelings about appearance and internalization of body ideals. Journal of Adolescence, 36, 485-493.

Webb, H. J., \& Zimmer-Gemback, M. J. (2014). The role of friends and peers in adolescent body dissatisfaction: A review and critique of 15 years of research. Journal of Research on Adolescence, 24, 564-590.

Williams, K. C., \& Page, R. A. (2011). Marketing to the generations. Journal of Behavioral Studies in Business, 3, 1.

Woods, H. C., \& Scott, H. (2016). Sleepyteens: social media use in adolescence is associated with poor sleep quality, anxiety, depression and low self-esteem. Journal of Adolescence, 51, 41-49.

Yang, M. (2013). Self-Esteem, Body Image and Appearance Management Behaviors among Korean and Caucasian-American Women: Associations to Attitudes toward Social Comparison and Model's Ethnicity in Advertisements. The Ohio State University.

Yoo, J. J., \& Kim, H. Y. (2012). Adolescents' body-tanning behaviours: influences of gender, body mass index, sociocultural attitudes towards appearance and body satisfaction. International Journal of Consumer Studies, 36, 360-366. https://doi.org/10.1111/j.1470-6431.2011.01009.x

Zhou, T. (2011). Understanding online community user participation: a social influence perspective. Internet Research, 21, 67-81. https://doi.org/10.1108/10662241111104884 